\title{
Tribocorrosion damage of a Jethete M152 type stainless steel
}

\author{
S.C. Wang ${ }^{\mathrm{a},{ }^{*}}$, S. Quinn ${ }^{\mathrm{b}}$, M.J. Starink ${ }^{\mathrm{a}}$, R.J.K. Wood ${ }^{\mathrm{a}, \mathrm{b}}$ and J.A. Wharton ${ }^{\mathrm{a}}$ \\ ${ }^{a}$ Materials Research Group, School of Engineering Sciences; University of Southampton, \\ Southampton, SO17 1BJ, United Kingdom \\ ${ }^{\mathrm{b}}$ Research Institute for Industry (RIfI), School of Engineering Sciences; University of Southampton, \\ Southampton, SO17 1BJ, United Kingdom
}

\begin{abstract}
An insert made from Jethete M152 type stainless steel (Fe-12Cr) was used for moulding a polymer product, but failed in-service due to the formation of oxidation/corrosion products. The investigation of the failure mechanism has been carried out using scanning and transmission electron microscopy (SEM and TEM). A high density of fine precipitates, 50-200 nm in size, were observed in the etched samples by SEM. TEM analysis combined with convergent beam electron diffraction (CBED) showed that the precipitates are $(\mathrm{Cr}, \mathrm{Fe}, \mathrm{Mo}){ }_{23} \mathrm{C}_{6}$ carbides which posses $\mathrm{Fm} \overline{3} \mathrm{~m}$ space group with a lattice parameter of $1.07 \pm 0.03 \mathrm{~nm}$. The formation mechanisms of the precipitates were studied by investigating a range of heat treatments.
\end{abstract}

Keywords: Precipitate; Oxidation; Jethete M152 alloy; Tribocorrosion.

* Corresponding author. Tel: +44 2380594638

E-mail address: wangs@,soton.ac.uk (S.C. Wang)

\section{Introduction}

$\mathrm{Fe}-12 \mathrm{Cr}$ (12 wt.\% Cr) steel alloys belong to the class of martensitic stainless steels and have a combination of properties which include good ductility at high strength levels, uniform properties throughout thick sections and favourable strength at temperatures up to about $480^{\circ} \mathrm{C}$ [1]. Stainless steels are iron-based alloys that contain a minimum of approximately $11 \mathrm{wt} . \% \mathrm{Cr}$, the amount needed to improve the corrosion performance. Martensitic stainless steels possess a body-centred tetragonal (bct) crystal structure after quenching from an austenite phase (face-centred cubic structure) at high temperature. The chromium content is generally in the range of 10.5 to 18.0 wt. $\%$, and carbon content may exceed $1.2 \mathrm{wt} . \%$. The chromium and carbon contents are carefully balanced to ensure a martensitic structure after hardening. Jethete M152 is a member of the Fe$12 \mathrm{Cr}$ family of alloys, with the addition of $\mathrm{Ni}$ and Mo. It features outstanding fracture toughness and good oxidation resistance up to approximately $425^{\circ} \mathrm{C}$, as well as the properties common to other Fe-12Cr alloys, noted above. These features, together with its favourable coefficient of expansion, make the alloy attractive for use for steam turbine components and compressor parts in gas turbine applications.

In this application Jethete M152 was used for a production tool, as a mould for manufacture of a polymer product. The operating conditions are a maximum temperature of approximately $230^{\circ} \mathrm{C}$ although the tool remains much cooler $\left(30\right.$ to $\left.40^{\circ} \mathrm{C}\right)$ and a pressure of approximately 1000 bar in an oxygen containing environment. Each tool is subjected to approximately 10, 000 cycles per day. Jethete M152 stainless steel was chosen for this application due to its corrosion resistance, however, in-service failures occurred and were linked to the formation of corrosion/oxidation products 
covering part of the surface. The purpose of this paper is to determine the possible failure mechanism, and to identify and analyse any deleterious phases present in the alloy.

\section{Experimental procedures}

Jethete M152 stainless steel was prepared using the vacuum induction melting (VIM) and vacuum arc remelting (VAR) processes, which results in a stainless steel of higher purity, lower nonmetallic inclusion content and fine grains. Inserts were fabricated after the alloys were softened at $690^{\circ} \mathrm{C}$ for $6 \mathrm{~h}$. The inserts were solution treated at $1050^{\circ} \mathrm{C}$ for $1 \mathrm{~h}$, oil quenched, and tempered at $560^{\circ} \mathrm{C}$ for $3 \mathrm{~h}$ followed by air cooling. The chemical composition of inserts is shown in Table 1.

Table 1. The chemical composition of the inserts (wt.\%)

\begin{tabular}{|c|c|c|c|c|c|c|c|c|c|c|}
\hline $\mathrm{C}$ & $\mathrm{Cr}$ & $\mathrm{Ni}$ & Mo & $\mathrm{Mn}$ & $\mathrm{V}$ & $\mathrm{Si}$ & $\mathrm{N}$ & $\mathrm{P}$ & $\mathrm{S}$ & $\mathrm{Fe}$ \\
\hline 0.12 & 11.4 & 2.72 & 1.64 & 0.58 & 0.31 & 0.23 & 0.024 & 0.023 & 0.005 & remainder \\
\hline
\end{tabular}

Samples of the failed and virgin (no prior operational service) insert components were investigated. To reveal the microstructure, inserts were sectioned, mounted in bakelite and wet ground on 120, 600, 1200 and 4000 grit SiC papers successively, and then etched for $30 \mathrm{sec}$ in a solution of $80 \mathrm{~cm}^{3}$ $\mathrm{HCl}, 5 \mathrm{~cm}^{3} \mathrm{HNO}_{3}, 1 \mathrm{~g} \mathrm{CuCl}_{2}$ and $20 \mathrm{~cm}^{3}$ distilled water. Microstructures were examined using a JEOL JSM-6500 FEG-SEM (field emission gun-scanning electron microscope), operating at $15 \mathrm{kV}$, with an Oxford Instruments energy dispersive X-ray spectrometry (EDS) analysis system. Discs of $3 \mathrm{~mm}$ in diameter were punched out from the slices of the specimens for Transmission Electron Microscopy (TEM) analysis, and then electropolished using a solution of $\mathrm{HNO}_{3}$ and methanol (1:3 in volume). The TEM foils were examined using a JEOL 3010 microscope operating at $300 \mathrm{kV}$.

\section{Results}

\subsection{Optical observation of the damaged edges of inserts}

Fig. 1 shows a macrograph of an insert which failed in-service. There are several scratches from top to bottom, which were formed during assembly of the insert into the sleeve component. Heavy stains (dark red by visual appearance) were associated with these scratches, although some stains occur on the insert surface where no scratches exist.

\subsection{SEM analysis of the oxidation/corrosion products}

Fig. 2a shows a secondary electron image (SEI) of one corrosion area on the insert, which corresponds to area 1 in Fig. 1. It appears that corrosion products are occurring preferentially in the scratches. Oxidation is present around the vast majority of the circumference of the outer rim of the insert and it varies in length along the insert at different circumferential positions. However, there was no evidence that oxidation/corrosion occurred preferably at grain boundaries. The backscatter electron image (BEI) at higher magnification (Fig. 2b) shows two kinds of morphologies: one is relatively bright (area A) and covering a substantial part of the surface, and the other is debris-like (area B). EDS confirms that the chemical composition at both areas have high oxygen contents, and the ratios of $(\mathrm{Fe}+\mathrm{Cr}) / \mathrm{O}$ are about 0.77 and 0.66 respectively, see Table 2. Such oxidation products are similar to those found on $\mathrm{Nd}-\mathrm{Fe}-\mathrm{B}$ alloys [2], where a $\mathrm{Fe}_{3} \mathrm{O}_{4}$ (magnetite) will form first and then transform into $\mathrm{Fe}_{2} \mathrm{O}_{3}$ (hematite) under further oxidation (including a small amount of $\mathrm{Cr}_{2} \mathrm{O}_{3}$ ). Therefore, it can be concluded that serious oxidation occurs in the scratches formed during operation. 
Table 2. The compositions of two typical oxidation / corrosion products (at.\%)

\begin{tabular}{cllllllcc}
\hline Area & $\mathrm{O}$ & $\mathrm{Si}$ & $\mathrm{Cr}$ & $\mathrm{Fe}$ & $\mathrm{Ni}$ & $\mathrm{Mo}$ & $(\mathrm{Fe}+\mathrm{Cr}) / \mathrm{O}$ & Products (ratio) \\
\hline $\mathrm{A}$ & 54.71 & 0.67 & 5.84 & 36.21 & 2.07 & 0.49 & 0.77 & $\mathrm{Fe}_{3} \mathrm{O}_{4}+\mathrm{Cr}_{2} \mathrm{O}_{3}(\sim 6: 1)$ \\
$\mathrm{B}$ & 58.40 & 2.00 & 3.95 & 34.76 & 0.16 & 0.73 & 0.66 & $\mathrm{Fe}_{2} \mathrm{O}_{3}+\mathrm{Cr}_{2} \mathrm{O}_{3}(\sim 9: 1)$ \\
\hline
\end{tabular}

It was also noted that some oxidation products occur on the insert surface, that are not associated with scratches, as shown in area 2 of Fig. 1. The corresponding BEI micrograph is shown in Fig. 3. The areas of dark colour were determined to be oxidation products of $\mathrm{Fe}_{2} \mathrm{O}_{3}$. The black particles were carbon rich, which was assumed to be due to contamination from polymer products manufactured at high temperature.

\subsection{SEM observation of the etched samples / TEM analysis}

After etching, distinct particles in the range of 50-200 $\mathrm{nm}$ are visible in an insert which failed during service, as shown in Fig. 4(a). EDS in SEM shows that the particles are chromium enriched. To help determine when this chromium enrichment occurs, an as-manufactured insert was also investigated. A transverse section was prepared from this virgin material. The high magnification micrograph in SEM (Fig. 4b) shows that there are chromium particles in the same size range as the virgin material. This indicates that the precipitates are introduced in the heat treatments during production of the raw material.

As X-rays activate an area $(0.5-1.0 \mu \mathrm{m}$ in steel bombarded at $15 \mathrm{kV})$ that is much larger than the dimension of the precipitates $(50-200 \mathrm{~nm})$, the composition of the precipitates cannot be determined accurately in SEM. The structure of these small precipitates is also difficult to identify by electron backscattering diffraction (EBSD) in SEM. TEM has therefore been utilised to analyse the structure information and the chemical composition of the precipitates. Fig. 5(a) shows two precipitates in bright field mode. The EDS spectrum in Fig. 5(b) confirms these particles are $\mathrm{Cr}$ rich, and also significant amounts of $\mathrm{C}, \mathrm{Mo}, \mathrm{Fe}$ and some $\mathrm{V}$ are detected. Table 3 shows the composition from EDS for one precipitate as well as the matrix. The composition of $\mathrm{C}$ is detected in variable from 13 to 20 at.\%. Figs. 5(c-e) show three selected area diffraction (SAD) patterns of the precipitate. These are fully consistent with [001], [112] and [111] zones in a face-centred cubic (fcc) structure. No forbidden reflection was observed. The corresponding lattice parameter $(a)$ was measured to be $1.07 \pm 0.03 \mathrm{~nm}$ (using the $\mathrm{Al}$ matrix as a reference).

Table 3. Chemical compositions of the unknown fcc phase determined from EDS (at. \%)

\begin{tabular}{lllllllll}
\hline Phase & $\mathrm{C}$ & $\mathrm{Si}$ & $\mathrm{V}$ & $\mathrm{Cr}$ & $\mathrm{Mn}$ & $\mathrm{Fe}$ & $\mathrm{Ni}$ & $\mathrm{Mo}$ \\
\hline Precipitate 1 & 20.2 & 0.1 & 1.6 & 51.6 & 0.4 & 19.0 & 0.7 & 6.4 \\
\hline Matrix & 3.8 & 0.6 & 0.2 & 12.7 & 0.4 & 78.6 & 2.6 & 1.1 \\
\hline
\end{tabular}

In three dimensions, the space groups specify the total symmetry of the arrangement of atoms in a crystal. The 230 Space Groups result from the systematic combination of the 14 Bravais lattices with the 32 Crystallographic Point Groups and the screw axis/translation element. The diffraction micrographs in Figs. 5(c-e) evidence that the precipitates has fcc structure (one of 14 Bravais lattices) without any screw axis / translation element (no forbidden reflections). The point group of the precipitate is determined using convergent beam electron diffraction (CBED), which can distinguish all 32 possible point groups unambiguously even for the present very small precipitate. There are two specific kinds of symmetry to look at in CBED patterns: Bright-field (BF) symmetry and Whole-pattern (WP) symmetry. The BF symmetry refers to the symmetry of high-order-Lauezone (HOLZ) lines presented in the 000 disk. The WP symmetry is the symmetry of the HOLZ 
lines and zero-order-Laue-zone (ZOLZ) Kikuchi lines in the pattern as a whole. From the BF and WP symmetries of CBED patterns obtained from several prominent zone axes, it is possible to find one of 31 diffraction groups, and then the possible point group, based on Steeds and co-worker's work [3,4]. A [001] zone CBED pattern is shown in Fig. 6a. According to the principle of HOLZ line formation [5], HOLZ lines in BF disc correspond to those in higher order Laue ring, therefore the latter's symmetry refers to the BF symmetry. Kikuchi lines and bands show the ZOLZ symmetry. Consequently the symmetries of both Kikuchi and HOLZ lines represent the WP symmetry. As indicated by the arrow and $\mathrm{m}$ (mirror) in Fig. 6a, the BF symmetry and the WP symmetry both show 4-fold axis and mirror, i.e. $4 \mathrm{~mm}$. The [111] zone CBED pattern is shown in Fig. 6b. Similarly, the symmetries of both BF and WP are $3 \mathrm{~m}$ because the HOLZ ring and the array of HOLZ-deficient Kikuchi lines show threefold symmetry with one mirror plane reproduced every $120^{\circ}$. The results are summarised in columns 2 and 3 of Table 4 . Further possible diffraction groups and point groups can be deduced according to the work of Refs [3,4] as shown in Table 3 . The point group for the precipitate, therefore, is $\mathrm{m} \overline{3} \mathrm{~m}$ as it satisfies the symmetries of both [001] and [111] zones. Combined with the Bravais lattices, it is possible to identify the space group of the crystal of $\mathrm{Fm} \overline{3} \mathrm{~m}$.

Table 4. Determination of CBED symmetries and possible point groups

\begin{tabular}{ccccc}
\hline Zone & BF symmetry & WP symmetry & Possible diffraction groups & Possible point groups \\
\hline$[001]$ & $4 \mathrm{~mm}$ & $4 \mathrm{~mm}$ & $4 \mathrm{~mm}$ or $4 \mathrm{~mm} 1_{\mathrm{R}}$ & $4 \mathrm{~mm}, 4 / \mathrm{mmm}$ or $\mathrm{m} \overline{3} \mathrm{~m}$ \\
\hline$[111]$ & $3 \mathrm{~m}$ & $3 \mathrm{~m}$ & $3 \mathrm{~m}$ or $6_{\mathrm{R}} \mathrm{mm}_{\mathrm{R}}$ & $3 \mathrm{~m}, \overline{3} \mathrm{~m}, 4 \overline{3} \mathrm{~m}$ or $\mathrm{m} \overline{3} \mathrm{~m}$ \\
\hline
\end{tabular}

\section{Discussion}

\subsection{Thermodynamics of oxidation}

When a metal is exposed to an oxidising environment at elevated temperatures, such as an environment that contains molecular oxygen $\left(\mathrm{O}_{2}\right)$, degradation can occur by direct action of the gas, without the need for the presence of a liquid electrolyte. This type of degradation/corrosion is often referred to as tarnishing, high-temperature oxidation, or scaling. The rate of attack increases substantially with temperature [6,7]. The EDS analysis, in Section 3.2, indicated that both $\mathrm{Fe}_{3} \mathrm{O}_{4}$ and $\mathrm{Fe}_{2} \mathrm{O}_{3}$ oxides were present in the oxidation products with small amounts of $\mathrm{Cr}_{2} \mathrm{O}_{3}$. The working temperature during operation was approximately $200^{\circ} \mathrm{C}$. According to the $\Delta \mathrm{G}^{\circ}-\mathrm{T}$ oxide formation ("Ellingham-Richardson") diagram [8], the formation of $\mathrm{Fe}_{3} \mathrm{O}_{4} / \mathrm{Fe}_{2} \mathrm{O}_{3}$ oxides is possible, as both reactions are exothermic:

$$
\begin{aligned}
& 3 \mathrm{Fe}+2 \mathrm{O}_{2} \rightarrow \mathrm{Fe}_{3} \mathrm{O}_{4} \\
& \Delta \mathrm{G}^{\circ}{ }_{200^{\circ} \mathrm{C}}=-210 \mathrm{~kJ} \\
& 4 \mathrm{Fe}_{3} \mathrm{O}_{4}+\mathrm{O}_{2} \rightarrow 6 \mathrm{Fe}_{2} \mathrm{O}_{3} \\
& \Delta \mathrm{G}^{\circ}{ }_{200^{\circ} \mathrm{C}}=-310 \mathrm{~kJ}
\end{aligned}
$$

In general, for oxidation-resistant $\mathrm{Fe}-\mathrm{Cr}$ steels to be fully effective they must contain sufficient chromium to form a thin protective oxide layer, consisting largely of $\mathrm{Cr}_{2} \mathrm{O}_{3}$, which acts as a barrier between the oxygen and the underlying metal. If the proportion of chromium is less that that required to provide complete protection, the chromium can also diffuse into the iron oxides formed. Low-chromium steels are reported to have an oxidation resistance similar to that of iron, however, at concentrations greater than 12 at. $\% \mathrm{Cr}$ and below $1000^{\circ} \mathrm{C}$ the oxidation resistance is increased almost a hundred-fold [9]. However, oxidation will occur more readily when the $\mathrm{Cr}$ content in the matrix falls below the critical value (normally regarded as 12 at.\% or $11 \mathrm{wt} . \%$ [1]). As discussed 
below, a mechanism that reduces $\mathrm{Cr}$ content in the matrix, is thought to occur in the material of the present study.

\subsection{Mechanisms of oxidation}

Oxidation appears to occur preferentially at the scratched sites on the insert and therefore the relationship between this oxide formation and the scratches caused when the insert is assembled into a sleeve is considered.

The oxidation resistance of steel is determined by the composition and thickness of the oxide layer. The existence of $\mathrm{Cr}$ oxides will prohibit the contact between iron and oxygen and therefore further oxidation can be prevented. A hard and thick oxide layer with a high $\mathrm{Cr}$ content will minimise chemical as well as mechanical oxidation and lengthen the lifetime of components. Auger electron spectroscopy (AES) analysis of the Fe-9Cr-1Mo (wt.\%) steel oxidation products has shown that the oxide layer forms a duplex structure consisting of $\mathrm{Fe}$ and $\mathrm{Cr}$ oxides, and the ratio of these two oxides varies with the oxidation temperature. Below $400^{\circ} \mathrm{C}$ the oxide layer consists mainly of $\mathrm{Fe}_{2} \mathrm{O}_{3}$, possibly $\mathrm{Fe}_{3} \mathrm{O}_{4}$ and a small amount of $\mathrm{Cr}_{2} \mathrm{O}_{3}$. The $\mathrm{Cr}_{2} \mathrm{O}_{3}$ oxide layer is reported to thicken as the temperature increases further [10]. In the present study, the virgin inserts were heat treated at $560^{\circ} \mathrm{C}$, resulting in the formation of a relatively thick $\mathrm{Cr}_{2} \mathrm{O}_{3}$ layer. The observed scratches were produced in the course of fitting the inserts thus damaging the integrity of the initial $\mathrm{Cr}_{2} \mathrm{O}_{3}$ oxidation film, and thus allowing the bare alloy to be exposed in the working environment at a temperature of $\sim 200^{\circ} \mathrm{C}$, in which $\mathrm{Fe}_{3} \mathrm{O}_{4}$ and $\mathrm{Fe}_{2} \mathrm{O}_{3}$ preferentially form.

Thus the above explanation is consistent with the observation that the oxidation is caused by the scratches which damage the thin oxidation protection layer. Indeed, significant corrosion/oxidation is noted to only occur within the scratches. In addition, for the failed inserts, oxidation was also present around a significant proportion of the outer rim circumference of the inserts, with or without scratches. This phenomenon can be related to a tribocorrosion mechanism in which a combination of oxidation and abrasive wear occurs (i.e. abrasion depassivates within scratches followed by oxidation of nascent scratch areas in oxygen environment). Oscillation of two metallic surfaces produces tiny metallic fragments that oxidise and become abrasive particles. Subsequent wear proceeds by mild adhesive wear in combination with abrasive wear.

The above oxidation mechanism via assembly scratches and tribocorrosion relies upon the $\mathrm{Cr}$ content being lower than $11 \mathrm{wt} . \%$, the amount required to form a continuous film of $\mathrm{Cr}_{2} \mathrm{O}_{3}$ with which to prevent the corrosion/oxidation. However, the studied alloy has a nominal $\mathrm{Cr}$ content above $11 \mathrm{wt} . \%$, which therefore should still be regarded as stainless. Therefore, possible depletion of the $\mathrm{Cr}$ content in the matrix of alloy needs to be considered. A possible mechanism for this is analysed below.

\subsection{Mechanisms of failure}

The most common mechanism for depletion of the $\mathrm{Cr}$ content in the matrix is due to the formation of particles which have a high percentage of $\mathrm{Cr}$. Therefore, the common $\mathrm{Cr}$-rich particles such as carbides $\left(\alpha^{\prime}\right)$ and sigma-phase $(\sigma)$ will be reviewed, and consideration of whether they could have formed in the present alloy will be made.

\section{Embrittlement at $475^{\circ} \mathrm{C}$ by $\alpha^{\prime}$}

After long-term service in the range of $300-500^{\circ} \mathrm{C}$, steels with more than $15 \%$ chromium become brittle and lose corrosion/oxidation resistance. This is referred to as $475^{\circ} \mathrm{C}$ embrittlement because peak hardness on ageing occurs at this temperature. The generally accepted mechanism is due to the precipitation of small spherical particles, $\sim 20 \mathrm{~nm}$ in diameter of a chromium rich $(80 \%)$ bcc phase $\alpha^{\prime}$ with a lattice parameter close to that of the matrix $\alpha$, first observed by TEM by Fisher et al. [11]. The precipitation of $\alpha^{\prime}$ in high purity Fe-Cr alloys can occur by either spinodal decomposition 
or by nucleation and growth, depending upon the composition and ageing temperature. However, $\alpha^{\prime}$ particles are rarely noted unless the chromium content exceeds $13 \%$. The particles observed in this study are therefore unlikely to be $\alpha^{\prime}$.

\section{Formation of sigma phase $(\sigma)$}

The properties of alloys subjected to $475^{\circ} \mathrm{C}$ embrittlement can be restored by heating above $538^{\circ} \mathrm{C}$; however excessive holding may result in sigma-phase $(\sigma)$ embrittlement, which in turn can be eliminated by heat treatment above $870^{\circ} \mathrm{C}$ [13]. Sigma-phase, often described as FeCr, is difficult to form in alloys with less than $20 \% \mathrm{Cr}$, but forms readily in alloys with $25-30 \% \mathrm{Cr}$ when heated between $500-800^{\circ} \mathrm{C}$. Elements such as $\mathrm{Mo}, \mathrm{Si}, \mathrm{Ni}$, and $\mathrm{Mn}$ shift the sigma-forming range to lower chromium contents. Sigma-phase consists of a tetragonal unit cell with lattice parameters of $a=$ $0.83-0.92 \mathrm{~nm}, \mathrm{c}=0.45-0.48 \mathrm{~nm}$ with the variations due to small changes in composition. The unknown phase in this study is not $\sigma$ phase, as the structure and lattice parameters have been shown to be very different. Laves phase (typical composition for $\mathrm{Cr}$ containing steels $\left.(\mathrm{Fe}, \mathrm{Cr})_{2}(\mathrm{Mo}, \mathrm{Nb}, \mathrm{Ti}, \mathrm{Si})\right)$ is another candidate [12], but its reported structure (hexagonal) is very different from the phase observed in the present alloy.

The formation of carbides degrades corrosion/oxidation resistance, and the formation of $\alpha^{\prime}$ or $\sigma$ phase is normally regarded as the reason for embrittlement. These phases are all Cr-rich, which depletes the $\mathrm{Cr}$ content in the adjacent matrix and thus causes sensitivity to corrosion/oxidation. As the present observed phase has a high $\mathrm{Cr}$ content, it is inevitable that the $\mathrm{Cr}$ content in the matrix has been reduced below 11 wt.\%, which is regarded as the lowest value to keep a steel stainless. Therefore, once the protected layer is broken down, the reduced $\mathrm{Cr}$ content of the matrix will cause a reduced resistance to oxidation and the high service pressures can induce brittle fracture at the thinner sections of the insert, i.e. the rim of the insert.

\section{Carbides}

Other reported Cr-rich phases, however, such as Laves $(\eta)$, Chi $(\chi)$, R, and Tau $(\tau)$ could be responsible for the reduction in $\mathrm{Cr}$ content of the matrix. However, none of these possess the fcc structure [12]. Three carbides are commonly observed in the present steel: $\mathrm{M}_{7} \mathrm{C}_{3}, \mathrm{M}_{23} \mathrm{C}_{6}, \mathrm{M}_{6} \mathrm{C}$ $[12,13] . \quad \mathrm{M}_{7} \mathrm{C}_{3}$ is present at tempering temperatures of approximately $480^{\circ} \mathrm{C} . \quad \mathrm{M}_{23} \mathrm{C}_{6}$ becomes the predominant carbide at $540^{\circ} \mathrm{C}$ and above. $\mathrm{M}_{7} \mathrm{C}_{3}$ seriously degrades corrosion resistance, as its presence depletes the chromium content in the matrix adjacent to Cr-rich particles. In this study, an fcc phase of $a=1.07 \pm 0.03 \mathrm{~nm}$ with $\mathrm{Cr}$ rich compositions detected with a carbon content from 1320 at.\%. It is therefore considered to be as carbides. The only fcc structure in carbides is $\mathrm{M}_{23} \mathrm{C}_{6}$ or $\mathrm{M}_{6} \mathrm{C}$ with carbide contents of 20.6 at.\% and 14 at.\%, respectively. It is hard to distinguish these two particles from EDS results as EDS measurement for light elements are always unstable. The further structure determination for this phase as $\mathrm{Fm} \overline{3} \mathrm{~m}$ exclude the $\mathrm{M}_{6} \mathrm{C}$ which has $\mathrm{Fd} \overline{3} \mathrm{~m}$ structure. Therefore they are thought to be $(\mathrm{Cr}, \mathrm{Fe}, \mathrm{Mo})_{23} \mathrm{C}_{6}$ carbides. These precipitates are preferably observed in the grain boundaries of austenite matrix [1], but in this study they seem to distribute within the grain. It is perhaps due to the martensite / ferrite matrix.

In fact, the precipitates could be as small as $10-20 \mathrm{~nm}$ in oil quenched samples as shown in Fig. 7(a). These precipitates will grow up to $50 \mathrm{~nm}$ after heating $560^{\circ} \mathrm{C}$ for $3 \mathrm{~h}$ (Fig. $7 \mathrm{~b}$ ). Further SEM analysis of samples subjected to additional heat treatments show that precipitation depends on the cooling rate; the faster the cooling rate, the larger the precipitates that form. The precipitates could be avoided at slow cooling speeds, such as air-cooling (Fig. 8) although they might be formed in the further heat treatment.

The present investigation thus indicates that the poor oxidation resistance performance of this alloy results from the formation of $\mathrm{Cr}$ rich $(\mathrm{Cr}, \mathrm{Fe}, \mathrm{Mo}){ }_{23} \mathrm{C}_{6}$ precipitates which deplete the $\mathrm{Cr}$ content in the matrix. 


\section{Conclusions}

An insert made from Jethete M152 type stainless steel, which failed in service, was investigated using scanning and transmission electron microscopy. A high density of Cr-rich precipitates has been observed by SEM. TEM analysis indicates that this is a $(\mathrm{Cr}, \mathrm{Fe}, \mathrm{Mo})_{23} \mathrm{C}_{6}$ carbides which posses $\mathrm{m} \overline{3} \mathrm{~m}$ structure with a lattice parameter of $1.07 \pm 0.03 \mathrm{~nm}$. The premature failure of these inserts is due to the formation of these $\mathrm{Cr}$-rich precipitates, which deplete the $\mathrm{Cr}$ in the adjacent matrix, and in turn reduce the oxidation resistance and induce embrittlement. This oxidation, in combination with subsequent abrasive and adhesive wear, led to the premature failure as a result of tribocorrosion.

\section{Acknowledgements}

The helpful technical discussions with Patrick Young are gratefully acknowledged

\section{References}

1 Davies JR (Ed). Stainless steels, ASM Specialty Handbook, ASM International, Ohio, 1994.

2 Davies MH, Mehl RF, Birchenall CE. J Metals 1951;3:889.

3 Buxton BF, Eades JA, Steeds JW, Rackham GM. Philos Trans R Soc London ser A1976;281:171-94.

4 Steeds JW, Vincent R. J Appl Cryst 1983;16:317-24.

5 Steeds JW. In: Hren JJ, Goldstein JI, Joy DC eds., Introduction to Analysis Electron Microscopy, New York: Plenum Press, 1979:387

6 Wright IG. High-Temperature Corrosion, Corrosion, Vol. 13, ASM Handbook, ASM International, $4^{\text {th }}$ ed. 1992, p.97-101.

7 Lai GY. in: High-Temperature Corrosion of Engineering Alloys, ASM International, 1990.

8 Richardson FD, Jeffes EJ. Iron Steel Inst 1948;160:261.

9 Shrier LL, Jarman RA, Burstein GT (Eds). Corrosion, $3^{\text {rd }}$ ed, Butterworth-Heinemann, Oxford, 1994.

10 Greeff AP, Louw CW, Swart HC. Corros Sci 2000;42:1725-40.

11 Fisher RM, Dulis EJ, Carroll KG. Trans AIME 1953;197:690.

12 San Martin D, Rivera Diaz del Castillo PEJ, Peekstok E, van der Zwaag S. Mater Chracter 2007:58:455-60.

13 Peckner D, Bernstein IM (Ed.), "Handbook of stainless steels", New York : McGraw-Hill, 1977. 


\section{Figures}

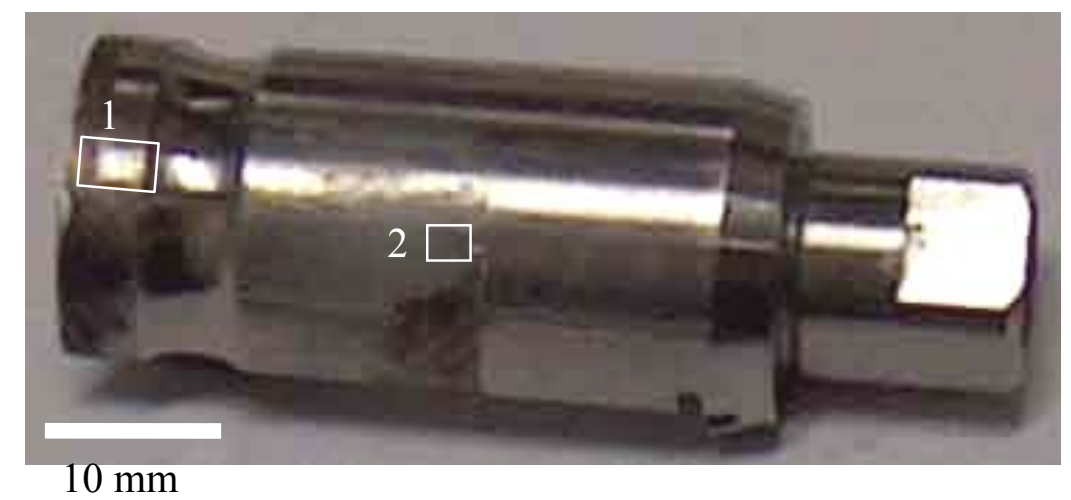

Fig. 1: A photograph of a failed insert after service.
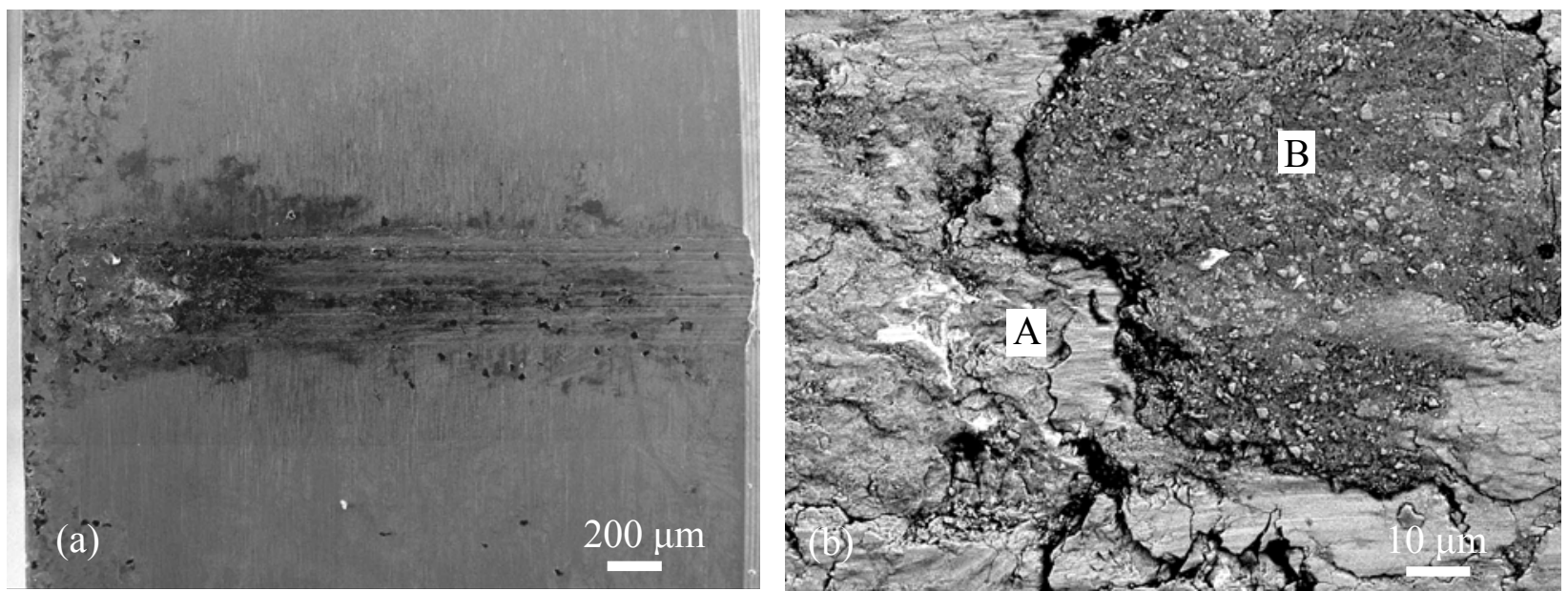

Fig. 2. SEM micrographs of area 1 of Fig.1 on the insert. (a) SEI at low magnification; (b) BEI at higher magnification.

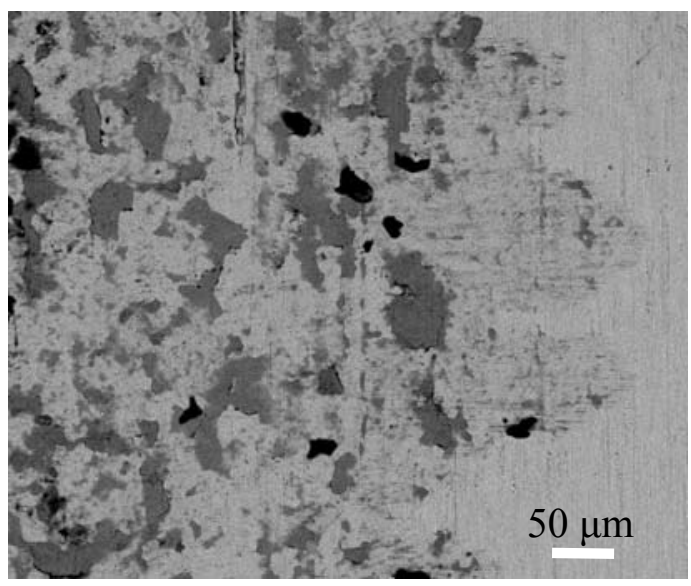

Fig. 3. BEI micrograph of area 2 of Fig. 1 

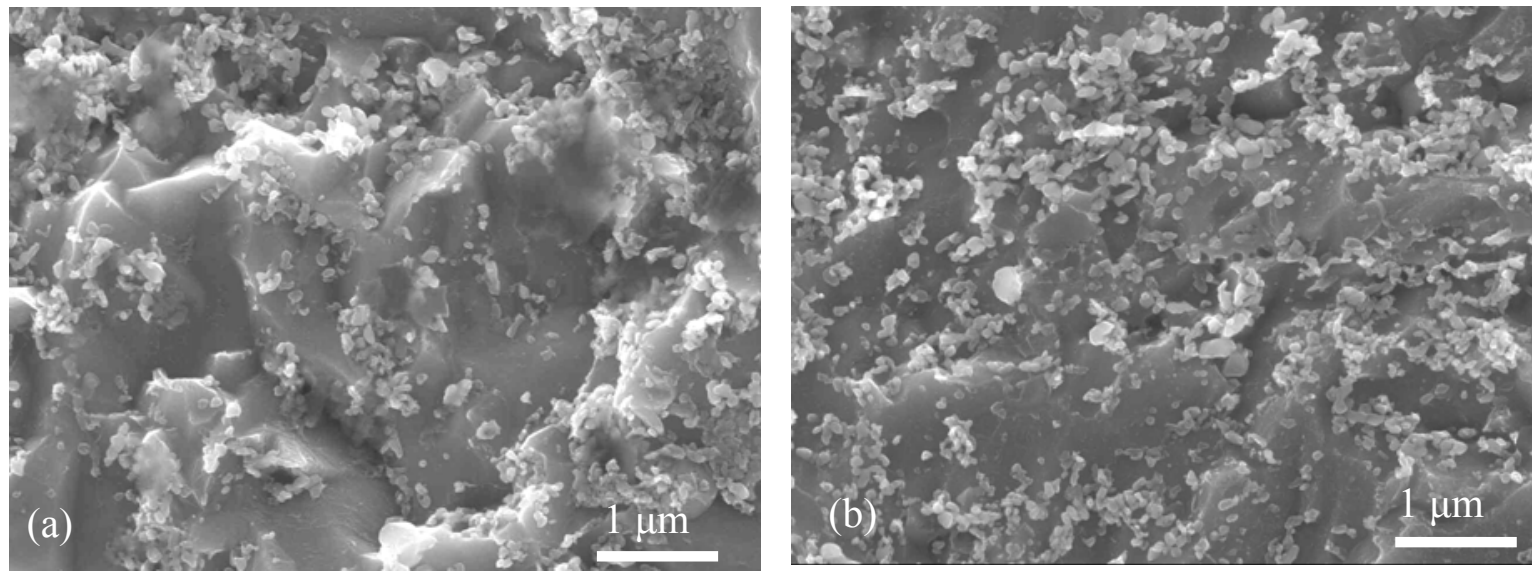

Fig. 4. SEI micrographs from the centre of the transverse sections

(a) insert that failed in service; (b) virgin inset (prior to service).
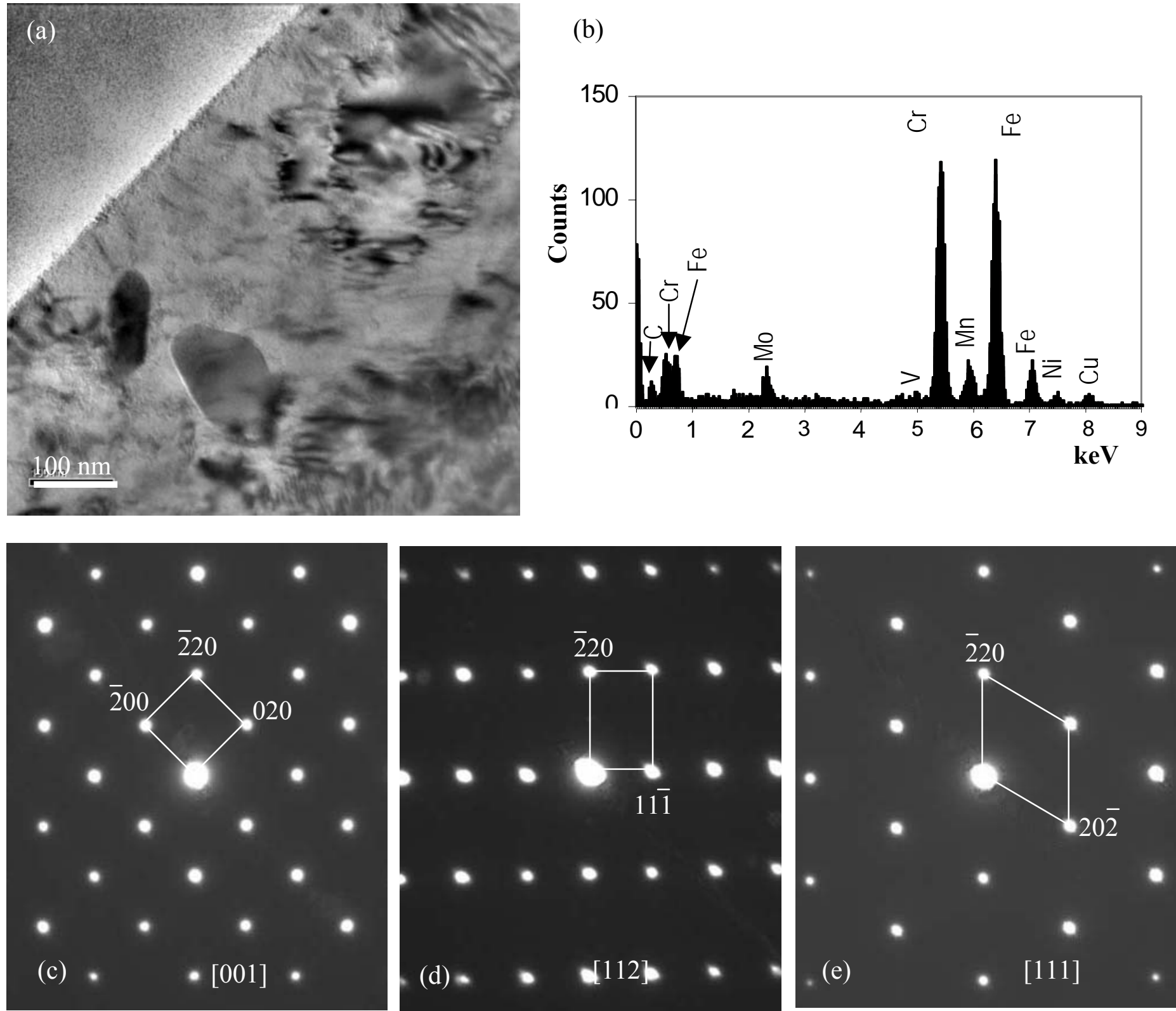

Fig. 5. TEM bright field image and the selected area diffraction pattern from the precipitates.

(a) bright field image; (b) EDS analysis of the precipitate

(c-e) [001], [112] and [111] diffraction patterns of the precipitate, respectively. 

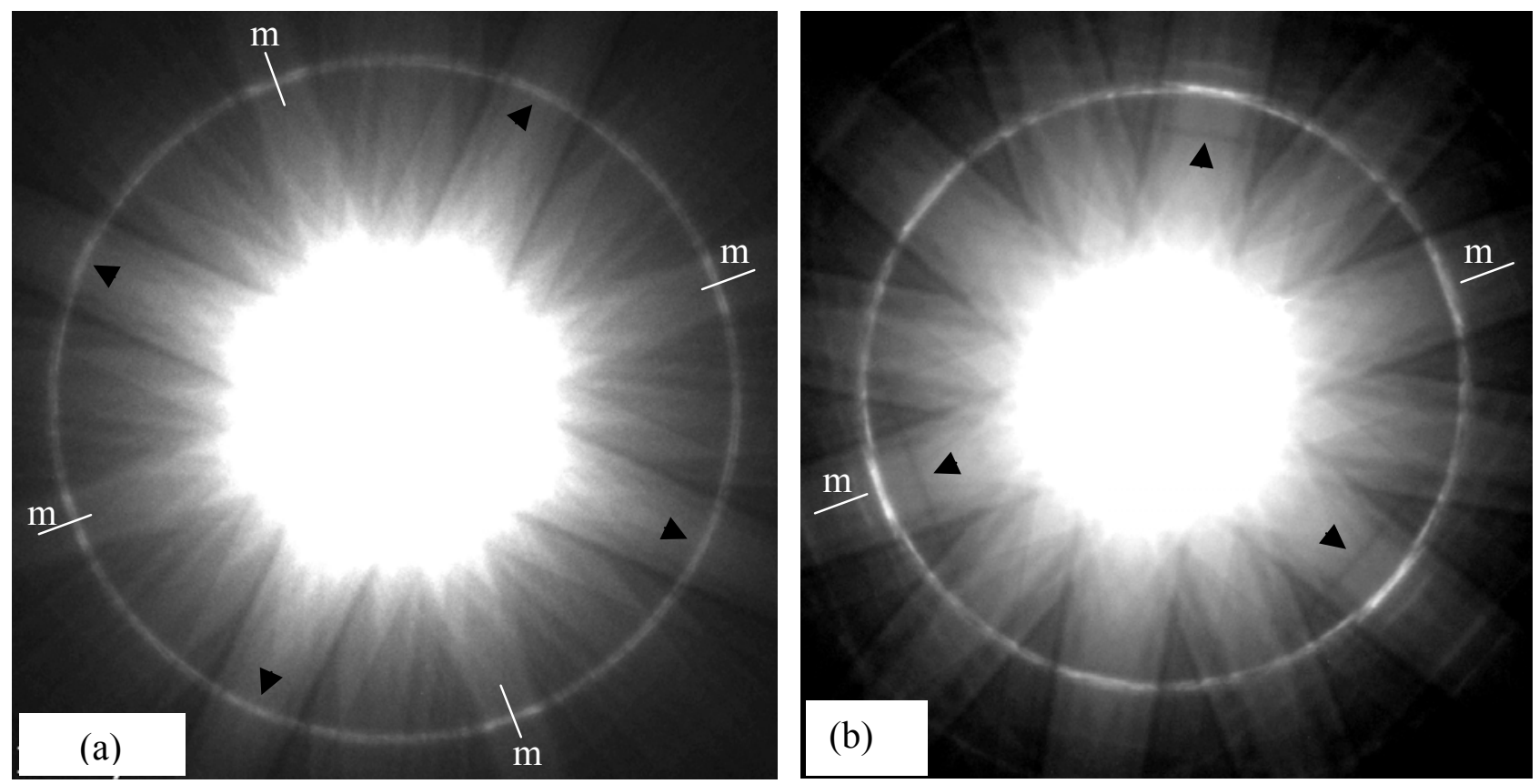

Fig. 6. Covergent beam electron diffraction patterns of (a) [001] and (b) [111] zones, which are corresponding to the SAD patterns of Figs. 5(c) and 5(e), respectively. $m$ represents a mirror symmetry. 

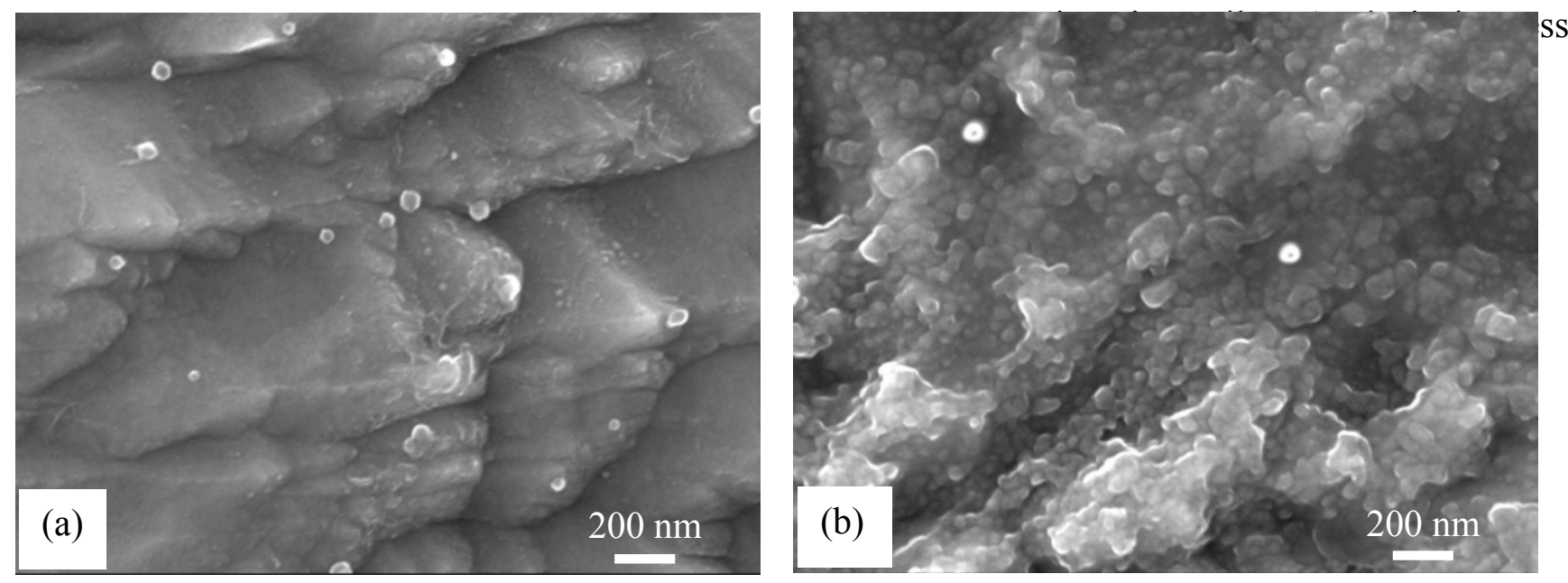

Fig. 7. SEI micrographs of one insert after (a) solution treatment at $1050^{\circ} \mathrm{C}$ for $1 \mathrm{~h}$, oil quenched and (b) further heat treatment at $560^{\circ} \mathrm{C}$ for $3 \mathrm{~h}$.
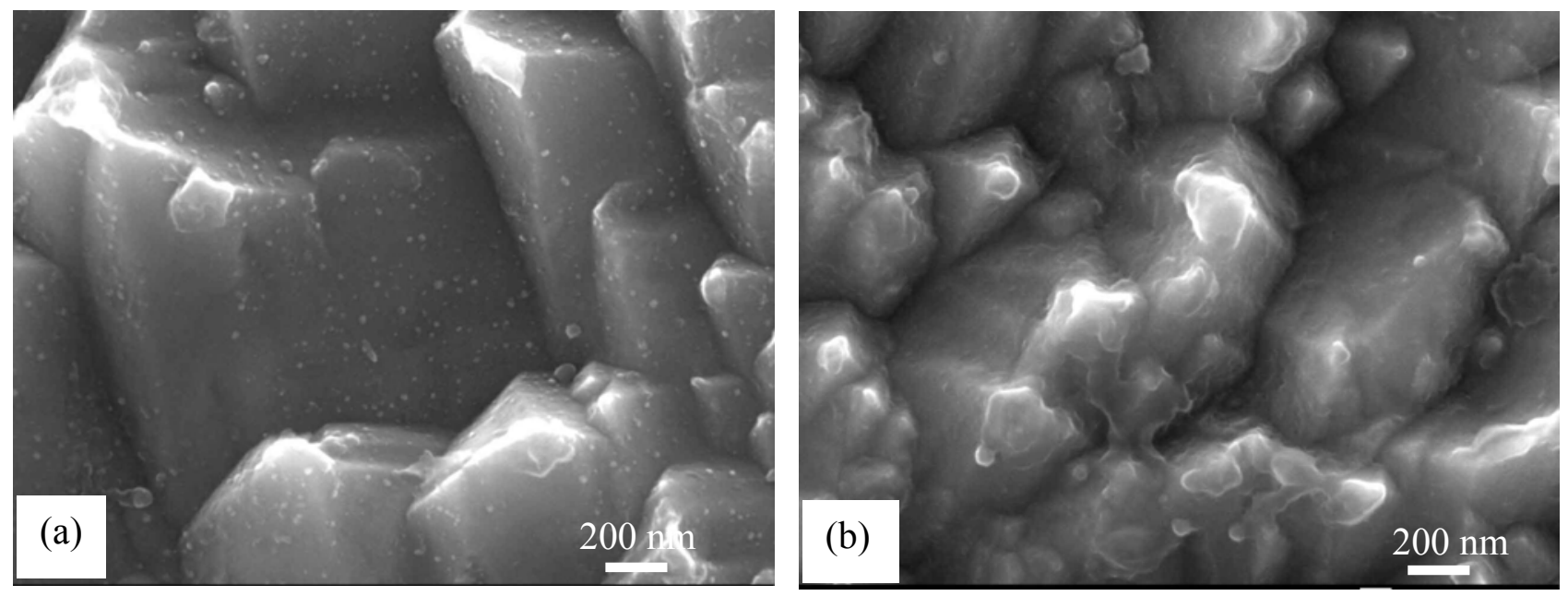

Fig. 8. SEI micrographs of one insert after (a) solution treatment at $1050^{\circ} \mathrm{C}$ for $1 \mathrm{~h}$, and subsequent water quenching and (b) air cooling. 